\title{
O JUDICIAL REVIEW E O ATIVISMO JUDICIAL DA SUPREMA CORTE AMERICANA NA PROTEÇÃO DE DIREITOS FUNDAMENTAIS
}

\author{
THE JUDICIAL REVIEW AND THE JUDICIAL ACTIVISM OF THE SUPREME COURT OF THE UNITED \\ STATES IN THE PROTECTION OF FUNDAMENTAL RIGHTS
}

Estefânia Maria de Queiroz Barboza*

Katya Kozicki**

Resumo: No presente artigo examinaram-se as origens históricas do judicial review nos Estados Unidos da América desde o caso Marbury v. Madison até a Corte Burger, bem como os reflexos de sua concepção no chamado "ativismo judicial" norte-americano, o qual acabou por priorizar o papel da jurisdição constitucional na proteção dos direitos fundamentais garantidos na Constituição, mesmo que isso implicasse enfrentar questões tipicamente políticas. Ou seja, apresentaram-se casos nos quais a Suprema Corte atuou de forma ativista especialmente na proteção de direitos fundamentais, embora em outros momentos tenha atuado justamente no sentido contrário, como na Era Lochner, numa postura conservadora em relação à proteção de direitos.

Palavras-chave: Ativismo judicial. Suprema Corte. Estados Unidos. Judicial Review.

\begin{abstract}
This article analyses the historical origins of judicial review in the United States since the Marbury v. Madison to Burger Court, as well as the reflections of its conception in the so-called American "judicial activism", which ended up prioritizing the role of the constitutional jurisdiction in the protection of the fundamental rights guaranteed in the Constitution, even if this involved judging political issues. In other words, there have been cases in which the Supreme Court has acted in an activist way, especially in the protection of fundamental rights, although at other times it has acted in the opposite direction, as in the Lochner Era, in a conservative position.
\end{abstract}

Keywords: Judicial activism. Supreme Court of the United States. Judicial Review.

\footnotetext{
"Doutora e Mestre em Direito pela Pontifícia Universidade Católica do Paraná; Professora Adjunta de Direito Constitucional e Teoria do Estado na Universidade Federal do Paraná; Professora do Programa de Mestrado Acadêmico em Direito no Centro Universitário Internacional Uninter; Rua do Rosário, 147, Centro, 80020-110, Curitiba, Paraná, Brasil; estefaniaqueiroz@uol.com.br " Doutora e Mestre em Direito pela Universidade Federal de Santa Catarina; Professora titular na Pontifícia Universidade Católica do Paraná; Professora associada de graduação e pós-graduação em Direito na Universidade Federal do Paraná; Rua Imaculada Conceição, 1155, Prado Velho, 80215-901, Curitiba, Paraná, Brasil; kkozicki@uol.com.br
} 


\section{Introdução}

No presente trabalho, examinaram-se as origens históricas do judicial review nos Estados Unidos da América e os reflexos de sua concepção no chamado "ativismo judicial" norte-americano, o qual acaba por priorizar o papel da jurisdição constitucional em prejuízo ao princípio democrático, na proteção dos direitos fundamentais garantidos na Constituição. Ou seja, acredita-se que a Suprema Corte é a instituição do Governo mais bem-preparada para pronunciar e guardar os valores permanentes da sociedade, que, por sua vez, não estão prontos, precisando ser continuamente derivados e enunciados. ${ }^{2}$

Justifica-se a opção por aprofundar o estudo da experiência norte-americana, visto que a introdução da jurisdição constitucional, tanto no Brasil quanto nos países europeus, teve por influência a experiência do judicial review estadunidense, bem como por se tratar da primeira experiência de controle de constitucionalidade no mundo.

Embora a Europa tenha rejeitado o modelo estadunidense de controle difuso de constitucionalidade das leis em virtude do receio do "governo de juízes", haja vista a atuação da Suprema Corte norte-americana na primeira metade do século XX, ${ }^{3}$ é certo que os modelos de constituição rígida e, consequentemente, de supremacia da constituição, adotados pelos países europeus em meados do século XX, têm origem no sistema constitucional americano, o sistema precursor de controle judicial das leis provenientes do Poder Legislativo que acabou por irradiar efeitos por todo o mundo.

Um segundo motivo que torna relevante o estudo do modelo do judicial review norte-americano aparece na medida em que o papel criativo ${ }^{4}$ e ativista dos juízes no sistema estadunidense, na busca de soluções para problemas concretos, transformando questões políticas em jurídicas, não tem comparativos $^{5}$ no resto do mundo, resultando como o melhor exemplo de proteção e concretização

\footnotetext{
1 Tushnet (2007, p. 415) ressalta que a discussão sobre ativismo judicial nos Estados Unidos, embora centrada nas decisões da Suprema Corte, assumem posições diferentes: 1) decisões ativistas podem ser aquelas que invalidam a legislação; 2) aquelas que invalidam a legislação sem uma forte justificação segundo a pessoa que está usando o termo; 3) ou aquelas que impõem responsabilidades ou privilégios inesperados.

2 Nesse sentido, ver Bickel (1986, p. 11): "It is a premise we deduce not merely from the fact of a written constitution but from the history of the race, and ultimately as a moral judgment of the good society, that government should serve not only what we conceive from time to time to be our immediate material needs bus also certain enduring values. This in part is what is meant by government under law. But such values do not present themselves ready-made. They have a past always, to be sure, but they must be continually derived, enunciated, and seen in relevant application." "And Bickel believed the Supreme Court was 'the institution of our government' best equipped 'to be the pronouncer and guardian of such values'."

3 Cf. Favoreu (2004, p. 18 e ss.) e Cappelletti (1984, p. 116 e ss.).

4 O papel criativo que se defenderá no presente estudo é aquele proposto por Dworkin, ou seja, não se trata de papel criador ou discricionário, mas de buscar nos princípios constitucionais a resposta certa. A criatividade da interpretação judicial ocorre "[...] pelo fato de impor um propósito, uma justificativa para o texto legal ou a tradição que está sendo interpretada. O juiz não é livre para criar direito, pois sempre haverá um instrumento do qual ele pode se servir - os princípios políticos constitutivos daquela comunidade - para julgar o caso concreto e o qual afasta a possibilidade da discricionariedade judicial." (KOZICKI, 2000, p. 189).

5 Considerando o aparente caráter filosófico-abstrato e declamatório das Declarações francesas e, por conseguinte, de seus direitos fundamentais, afirmava-se a superioridade moral dos direitos, não se garantindo, porém, sua eficácia e efetividade no plano jurídico, tendo, inclusive, escrito Jellinek (apud VIEIRA DE ANDRADE, 2001, p. 21) que: "[...] sem a América, sem as constituições dos seus diversos Estados, talvez tivéssemos uma filosofia de liberdade, mas nunca teríamos uma legislação que garantisse a liberdade."
} 
dos direitos fundamentais de que se tem conhecimento, mesmo que essa proteção tenha significado a oposição da Suprema Corte americana às pretensões políticas da maioria.

Esse protagonismo do Judiciário é, muitas vezes, chamado de ativismo judicial, o qual deve ser entendido não como o quanto uma Corte é ocupada mas como o quanto seus juízes estão dispostos a desenvolver o direito. Nesse sentido é que no presente artigo se apresentam as principais decisões que demonstram o ativismo judicial da Suprema Corte Americana, seja em momentos progressistas, seja em momentos mais conservadores da Corte, quando aparecem os críticos ao ativismo.

Assim, no presente artigo trata-se, num primeiro momento, do caso Marbury v. Madison, não somente por ser o primeiro caso a definir o papel de controle de constitucionalidade da Suprema Corte Americana, mas porque foi ativista na medida em que estabeleceu um poder não previsto na Constituição Americana. Também enfrenta o mais vergonhoso caso da Suprema Corte Americana, Dred Scott v. Sandford, num ativismo criticado uma vez que legitimou o regime escravagista americano, sendo o estopim da Guerra Civil.

Buscou-se, ainda, estudar a Corte na Era Lochner, na qual o ativismo conservador invalidou diversas leis que buscavam a intervenção do Estado na economia após a crise de 1930, sofrendo, portanto, uma crítica por parte da doutrina americana, que acabou por defender, nesse período, uma maior deferência ao Parlamento.

A Corte Warren também é tratada, uma vez que representa o paradigma constitucional do pós-guerra nos Estados Unidos, sendo vista como a Corte que melhor protegeu os direitos fundamentais das minorias.

A Corte Burger, por sua vez, também aparece com importância, pois passa a proteger direitos não enumerados na Constituição americana, com base na Nona Emenda, e, portanto, também tem sua atuação vista como ativista, no sentido de avançar na proteção de direitos fundamentais.

Embora existam outras decisões importantes da Suprema Corte Americana julgadas mais recentemente, no presente artigo buscou-se trazer um panorama histórico dos momentos principais que fortaleceram o papel ativista da Corte.

\section{0 caso Marbury v. Madison}

É interessante ressaltar que o maior poder da Suprema Corte americana, qual seja, o de fazer a revisão judicial de constitucionalidade dos atos dos outros Poderes, seja em âmbito federal, seja estadual, não está previsto em nenhuma norma expressa da Constituição daquele país, o que "[...] não quer dizer que o poder da 'judicial review' não pode ser colocado na Constituição, mas apenas que ele não pode nela ser achado." (BICKEL, 1986, p. 1).

O artigo $6^{\circ}$, cláusula $2^{\mathrm{a}}$ da Constituição norte-americana de 1787 estabelecia que:

This Constitution, and the Laws of the United States which shall be made in Pursuance thereof; and all Treaties made, or which shall be made, under the Authority of the United States, shall be the supreme Law of the Land; and the Judges in every State 


\section{shall be bound thereby, any Thing in the Constitution or Laws of any State to the Contrary notwithstanding. ${ }^{6}$}

Foi justamente com base neste artigo que se fundamentou a primeira ${ }^{7}$ e mais famosa decisão da Suprema Corte dos Estados Unidos da América, que pode ser considerada como a origem do judicial review, ${ }^{8}$ tendo sido proferida pelo Chief Justice John Marshall, considerado por muitos o melhor juiz da Suprema Corte de todos os tempos, no caso Marbury versus Madison, em 1803.

Vale aqui reproduzir as circunstâncias históricas e o contexto em que o caso ocorreu.

Nas eleições presidenciais de 1800, Thomas Jefferson, republicano, derrota John Adams, federalista, vindo a ser o novo Presidente dos Estados Unidos. No entanto, antes de terminar seu Governo, enquanto ainda detinha maioria no Congresso, John Adams, de forma a manter seu controle político por meio do Poder Judiciário, consegue a aprovação de uma lei que reduz o número de ministros da Suprema Corte e cria 16 cargos novos de juízes federais, os quais são nomeados nos últimos momentos do mandato pelo Presidente então derrotado (BARROSO, 2004, p. 3).

Do mesmo modo, aprovou-se, em fevereiro de 1801, outra lei que permitia ao Presidente nomear 42 juízes de paz, cujos nomes foram confirmados pelo Senado na véspera da posse do novo Presidente.

William Marbury, por sua vez, fora legalmente nomeado juiz de paz do Distrito de Columbia. Apesar disso, "Madison, Secretário do Governo, seguindo instruções de Jefferson, o novo Presidente, negara-lhe a posse." (RODRIGUES, 1992, p. 35). Assim, em 17 de dezembro de 1801, Marbury impetrou a writ of mandamus contra Madison, para que lhe empossasse, "[...] com base em uma lei de 1789 (the Judiciary Act), que havia atribuído à Suprema Corte competência originária para processar e julgar ações daquela natureza" (BARROSO, 2004, p. 4), ou seja, contra autoridades federais.

Ainda, o Congresso, em 1802, revogou aquela lei que havia criado os cargos de juízes de paz. Madison sequer respondeu à ação, por acreditar "[...] that the judges had no right to issue such an order to the executive, a coequal branch" (WOLFE, 1994, p. 80), deixando a causa correr à revelia.

A questão estava se tornando mais política do que jurídica, chegando os republicanos a afirmar que não cumpririam eventual decisão tomada pela Suprema Corte, tendo o Congresso inclusive declarado que "[...] any attempt of federalism to exalt the Judiciary over the Executive and Legislature, and to give that favorite department a political character $\&$ influence would terminate in the degradation and disgrace of the judiciary." (NELSON, 2000, p. 58). Cabe aqui ressaltar que John Marshall, antes de ser Chief of Justice, era Secretário de Estado do Presidente Adams e, portanto, tinha sido indicado pelo governo federalista. Ou seja, a composição da Suprema Corte era basicamente de federalistas indicados pelo governo anterior, a qual teria que apreciar lei aprovada pelo Congresso já totalmente renovado por republicanos.

\footnotetext{
6 Disponível em: < http://www.law.ou.edu/ hist/constitution/>. Acesso em: 25 jun. 2005.

7 Ressalta-se que antes de Marbury v. Madison existem registros de outras decisões de judicial review por juízes federais. Para saber mais, ver Wolfe (1994, p. 80).

8 Hamilton (2005, p. 469 e ss.) já defendia the Judges as Guardians of the Constitution no Federalista n. 78.
} 
Contudo, sabiamente John Marshall conseguiu se afastar das pressões políticas envolvidas no caso, e decidiu que apesar de Marbury ter direito a ser empossado, a Suprema Corte não tinha competência para decidir o caso, uma vez que entendeu que o Judiciary Act de 1789, que atribuía competência à Suprema Corte para decidir causas como esta, era inconstitucional.

Veja-se o relato de Bickel (1986, p. 3) a respeito:

Marshall held that Marbury and the others were entitled to their commissions, but that the Supreme Court was without power to order Madison to deliver, because the section of the Judiciary Act of 1789 that purported to authorize the Court to act in such a case as this was itself unconstitutional. Thus did Marshall assume for his court what is nowhere made explicit in the Constitution - the ultimate power to apply the constitution, acts of Congress to the contrary notwithstanding.

Dessa forma, Marshall decidiu que a Constituição é uma lei suprema, e que, por conseguinte, os atos legislativos ordinários devem estar em conformidade com ela, pois um ato legislativo contrário à Constituição não é lei e, consequentemente, não deve a Corte aplicá-lo ou dar-lhe efetividade, sob pena de se entender que "[...] written constitutions are absurd attempts, on the part of the people, to limit a power in its own nature ilimitable." E conclui que, se duas leis estão em conflito, então a Corte deve obedecer à superior e aplicá-la.

Para Bickel (1986), Marshall sabia que em muitos casos era difícil demonstrar a contrariedade do ato legislativo à Constituição, que, em sua maioria, não era evidente, e que era uma questão de política que alguém o decidisse. O problema era quem: as Cortes, o próprio Poder Legislativo, o Presidente, os júris ou o povo por meio de processo eleitoral? (BICKEL, 1986, p. 3).

Logo, Marshall, ao entender que aquela lei ordinária não poderia ampliar competência originária da Suprema Corte, diferente do que estava previsto na Constituição, chegou ao problema central, ou seja, se poderia a Suprema Corte deixar de aplicar uma lei inconstitucional, entendendo-a como inválida (BARROSO, 2004, p. 8).

Confira-se trecho da decisão de Marshall:

[...] emphatically the province and duty of the judicial department to say what the law is [...] If two laws conflict[ed] with each other, the courts must decide on the operation of each.

So if a law be in opposition to the constitution; if both the law and the constitution apply to a particular case, so that the court must either decide that case conformably to the law, disregarding the constitution; or conformably to the constitution, disregarding the law; the court must determine which of these conflicting rules governs the case. This is of the very essence of judicial duty.

If then, [...] the constitution is superior to any ordinary act of the legislature, the constitution, and not such ordinary act, must govern the case to which they both apply.

Those then who controvert the principle that the constitution is to be considered, in court, as a paramount law, are reduced to the necessity of maintaining that courts must close their eyes on the constitution, and see only the law.

This doctrine would subvert the very foundation of all written constitutions. It would declare that an act which, according to the principles and theory of our government, is enti-

\footnotetext{
9 “[...] constituições escritas são tentativas absurdas, por parte do povo, para limitar uma força que é ilimitável por sua própria natureza." Marburyv. Madison, 5 U.S. 137. Disponível em: <https://www.law.cornell.edu/supremecourt/text/5/137\#>. Acesso em: 15 set. 2016.
} 
rely void, is yet, in practice, completely obligatory. It would declare that if the legislature shall do what is expressly forbidden, such act, notwithstanding the express prohibition, is in reality effectual. It would be giving to the legislature a practical and real omnipotence, with the same breath which professes to restrict their powers within narrow limits. It is prescribing limits, and declaring that those limits may be passed at pleasure.

That is thus reduces to nothing what we have deemed the greatest improvement on political institutions - a written constitution - [is] sufficient, in America, where written constitutions have been viewed with so much reverence for rejecting the construction. ${ }^{10}$

Da leitura dessa decisão, podem-se verificar os principais fundamentos que justificaram a defesa do controle judicial de constitucionalidade por Marshall: é dever do Judiciário interpretar a lei e a Constituição; a Constituição é superior aos atos legislativos ordinários, como consequência de uma Constituição escrita e rígida; os atos legislativos em desconformidade com a Constituição devem ser declarados nulos; pensar que a Constituição não impõe limites ao Legislativo seria como atribuir a este poderes incontroláveis.

Na verdade, Hamilton (2005, p. 469 e ss.) já tinha declarado no "Federalista 78" tanto a supremacia da Constituição quanto o papel da Suprema Corte de intérprete maior da Constituição, ressaltando que, ao se permitir que o Judiciário declare nula uma lei votada pelo Legislativo, não quer dizer que aquele é superior a este, mas que a vontade do povo, representada na Constituição, vale mais do que a vontade de seus representantes, expressa na legislação ordinária. Entretanto, o mérito de Marshall consiste na positivação desses princípios, e o fazendo em um caso no qual julgou a favor de seu adversário político.

Assim, conseguiu demarcar o poder da Suprema Corte de rever atos legislativos estaduais e federais que contrariassem a Constituição americana, de uma forma deveras inteligente, visto que seus adversários políticos tiveram que aceitar a decisão, a qual lhes havia sido favorável (BARROSO, 2004, p. 9), restando a decisão proferida por Marshall no caso Marbury versus Madison, como o marco do controle de constitucionalidade no constitucionalismo moderno.

Mas, para além disso, conforme anota Campos (2014, p. 52), o caso em tela foi ativista em dois aspectos: primeiro porque a Corte não foi deferente ao Congresso, segundo porque apesar de a Constituição não estabelecer a competência da Corte para realizar o controle de constitucionalidade das leis,

\footnotetext{
$\overline{10}$ "[...] enfaticamente é função e dever do departamento judicial de dizer o que a lei é [...] se duas leis se conflitam (conflita$\mathrm{ram}$ ) entre si, as cortes devem decidir na execução de uma delas. Portanto se a lei se opõe à constituição, se tanto a lei quanto a constituição servem para um caso particular, então a corte deve decidir se aquele caso está conforme a lei, desconsiderando a constituição, ou se está conforme a constituição, desconsiderando a lei; a corte deve determinar qual dessas regras que se divergem será aplicada no caso. Isto é a essência do dever judicial. Se então, a constituição é superior a qualquer ato comum do legislativo, a constituição, e não tal ato, deve reger o caso em que os dois se aplicam. Aqueles, então, que são contra o princípio de que a constituição deve ser considerada, no âmbito da corte, como a lei suprema, são reduzidas as necessidades de se sustentar que cortes devam fechar seus olhos para a constituição, e verem somente a lei. Essa doutrina subverteria a base de todas as constituições escritas. Iria declarar que um ato que, estando de acordo com os princípios e a teoria do nosso governo, é totalmente vazio, é ainda, em prática, completamente obrigatório. Declararia que se o Legislativo deve fazer o que é expressamente proibido, tal ato, apesar da expressa proibição, é em realidade efetivo. Estaria dando ao Legislativo uma prática e uma real onipotência, com o mesmo fôlego que afirma restringir seus poderes dentro de limites estreitos. Isto significaria prescrever limites, e declarar, ao mesmo tempo, que esses limites podem ser transgredidos como se bem entender. Isto, então, reduziria a nada o que julgamos a maior evolução em instituições políticas - uma constituição escrita - (é) suficiente, na América, onde constituições escritas têm sido vistas com tanta reverência por rejeitar a construção." Marbury v. Madison, 5 U.S. 137. Disponível em: <https://www.law.cornell.edu/supremecourt/text/5/137\# > . Acesso em: 15 set. 2016.
} 
Marshall conseguiu estabelecer esse espetacular poder para a Suprema Corte americana. Por outro lado, é possível afirmar a autorrestrição da Corte ao se negar o poder de julgar altas autoridades do governo.

Por certo que o presente caso demonstra que o contexto político vai acompanhar a Corte em outros momentos de ativismo ou autorrestrição judicial.

\section{0 caso Dred Scott v. Sandford}

A segunda decisão da Suprema Corte norte-americana que veio a declarar a inconstitucionalidade de uma lei é a mais polêmica e a mais criticada ${ }^{11}$ de toda a história do judicial review, tendo sido proferida em 1857, sob a presidência de Taney, no caso Dred Scott versus Sandford. ${ }^{12}$

No caso em tela, a Suprema Corte declarou inconstitucional The Misouri Compromise que limitava a escravidão ao norte da linha de Mason-Dixon com base em um precedente que estabelecia que na volta a um Estado escravagista, o escravo, mesmo que tenha sido considerado livre em outro Estado, deve ser controlado pela lei desse Estado e, portanto, Dred Scott não tinha direito a continuar livre quando retornasse ao Estado do Misouri onde a escravidão era permitida. ${ }^{13}$ Não obstante, em vez de decidir apenas o caso em concreto, a Suprema Corte decidiu que os negros, "[...] ainda quando pudessem ser cidadãos à luz da legislação de algum Estado da Federação, não eram, todavia, cidadãos dos Estados Unidos"14 e, por essa razão, não poderiam ajuizar ações perante juízos e tribunais federais.

Nos fundamentos da decisão, além dos argumentos originalistas de que os negros não estariam incluídos e nem havia intenção dos fundadores de que eles fossem incluídos como cidadãos na Constituição, o que significaria, portanto, a impossibilidade de reivindicar quaisquer direitos assegurados aos cidadãos dos Estados Unidos, a Corte também trouxe argumentos morais bastante criticados, inclusive, na época, especialmente o de que seriam uma raça inferior e, portanto, subordinados aos brancos. Por outro lado, a Corte atua em deferência ao Poder Legislativo para não enfrentar o mérito da decisão ao estabelecer que:

It is not the province of the court to decide upon the justice or injustice, the policy or impolicy, of these laws. The decision of that question belonged to the political or law making power, to those who formed the sovereignty and framed the Constitution. The duty of the court is to interpret the instrument they have framed with the best lights we can obtain on the subject, and to administer it as we find it, according to its true intent and meaning when it was adopted.

\footnotetext{
11 Para Bruce Ackerman: "From a moral point of view, Dred Scott is the single darkest stain upon the Court's checkered history." "De um ponto de vista moral, Dred Scott é uma única mancha negra sobre a história da Corte.") (ACKERMAN, 1991, p. 63).

12 Scott v. Sandford, 60 U.S. 393. Disponível em: <https://www.law.cornell.edu/supremecourt/text/60/393\#writing-USSC_ CR_0060_0393_ZO>. Acesso em: 01 nov. 2016.

13 Scott v. Sandford, 60 U.S. 393. Disponível em: <https://www.law.cornell.edu/supremecourt/text/60/393\#writing-USSC_ CR_0060_0393_ZO>. Acesso em: 01 nov. 2016.

${ }_{14} \bar{S}$ cott v. Sandford, 60 U.S. 393. Disponível em: <https://www.law.cornell.edu/supremecourt/text/60/393\#writing-USSC_ CR_0060_0393_ZO>. Acesso em: 01 nov. 2016.
} 
A decisão repercutiu de forma bastante negativa e, segundo Bickel, foi o estopim para a guerra civil americana, já que Lincoln fez dessa decisão um pretexto para justificar a guerra. ${ }^{15}$ Pode-se, inclusive, argumentar que a ausência de proteção da minoria negra gerou ampla instabilidade política e social, levando à precipitação da guerra civil norte-americana.

Bickel (1962, p. 259) explica que Lincoln e o partido Republicano, assim como a maioria da nação americana, opuseram-se à decisão e ressalta, ainda, que Lincoln teria deixado claro sua oposição à decisão da Corte, que ele via como equivocada e sentia suas consequências, bem como defendia a possibilidade de a Corte estar errada, não havendo nada de sagrado em suas decisões.

Apesar do caráter extremamente negativo, vale a pena ressaltar que foi a primeira vez que a Suprema Corte americana atribuiu caráter substantivo ao princípio do devido processo legal, ao decidir que não era justo que um cidadão americano perdesse sua propriedade porque ele a levou a um território específico, sob pena de ofensa ao devido processo legal. ${ }^{16}$

Com essa decisão, a Suprema Corte perdeu bastante seu prestígio, sendo este, inclusive, o caso mais relembrado por aqueles que são contra o ativismo judicial.

Tribe (2008, p. 21) traz essa decisão como um dos exemplos paradigmáticos de como uma Constituição nunca mais deve ser lida, fornecendo, desse modo, fontes cruciais para a compreensão da Constituição, embora seja uma lição que não pode ser encontrada na linguagem visível da Constituição, mas exteriormente a seu texto.

\section{A Suprema Corte Americana na Era Lochner}

Já na Era Lochner, ${ }^{17}$ em um período conturbado, a Suprema Corte, sob a inspiração do Liberalismo econômico, declara inconstitucionais várias leis que, de alguma forma, permitiam a intervenção do Estado na economia.

A decisão mais famosa desse período foi em 1905, no caso Lochner v. New York, ${ }^{18}$ que envolvia uma lei de Nova York que limitava as horas de trabalho dos empregados de padaria em 60 horas semanais e 10 horas diárias. A Suprema Corte declarou inconstitucional a lei por entender que ela violava a liberdade contratual protegida pela cláusula do devido processo legal da Emenda 14 (WOLFE, 1994, p. 151):

\footnotetext{
15 "What he (Lincoln) not accept was the Dred Scott decision, the declaration that, by the law of the Constitution and conformably to the aspirations of the Declaration of Independence, the Negro was a chattel. He would not accept that, and he made it the casus belli." (BICKEL, 1986, p. 66).

${ }_{16}$ Scott v. Sandford, 60 U.S. 393. Disponível em: <https://www.law.cornell.edu/supremecourt/text/60/393\#writing-USSC_ CR_0060_0393_ZO>. Acesso em: 01 nov. 2016. "Thus, the rights of property are united with the rights of person, and placed on the same ground by the fifth amendment to the Constitution, which provides that no person shall be deprived of life, liberty, and property, without due process of law. And an act of Congress which deprives a citizen of the United States of his liberty or property merely because he came himself or brought his property into a particular Territory of the United States, and who had committed no offence against the laws, could hardly be dignified with the name of due process of law."

17 Rodrigues (1992, p. 99-101) caracteriza o período de 1895 até 1937 como "Governo dos Juízes", considerando a supremacia política do Judiciário sobre o Legislativo, limitando os poderes do Congresso.

18 Lochner v. New York, 198 U.S. 45. Disponível em: <https://www.law.cornell.edu/supremecourt/text/198/45>. Acesso em: 03 nov. 2016. Para saber mais a respeito, ver Campos (2014, p. 57 e ss.).
} 
Em todo caso que vier perante esta corte, quando legislação deste teor estiver em questão, e quando a proteção da Constituição Federal é invocada, surge necessariamente a questão: É este um justo, razoável e apropriado exercício do poder de polícia do estado, ou é esta uma desarrazoada, desnecessária e arbitrária intervenção no direito do indivíduo à sua liberdade pessoal, ou a intromissão nesses contratos de trabalho é apropriada ou necessária ao suporte do indivíduo e de sua família? Por certo, a liberdade de contrato de trabalho inclui o direito de ambas as partes a ela. Um tem tanto o direito de comprar como o outro de vender seu trabalho. ${ }^{19}$

Dessa decisão, verifica-se que a Suprema Corte fez uma análise substantiva da lei em face do princípio do devido processo legal, e não uma análise meramente procedimental, na medida em que verificou a justiça e a razoabilidade da lei, e não apenas se ela obedecera às formalidades do procedimento democrático. Ao se julgar se uma lei é justa ou razoável, o tribunal, necessariamente, faz um julgamento substantivo a respeito, até porque, ao decidir que a lei não tratava da questão da saúde do trabalhador - e, em consequência, de competência do Estado - já estava a fazer uma análise substantiva do caso em concreto.

Wolfe $(1994,151)$ vê esse caso como um dos primeiros casos de uma Era do Devido Processo Econômico, durante a qual a Corte sustentou uma maioria substancial de normas regulatórias que haviam sido questionadas perante a Corte. Mas ressalta que a Corte não manteve um comportamento uniforme, mas altos e baixos em seu próprio ativismo, seja tolerando mais a regulação econômica num momento, seja sendo mais restritiva com o poder de regulação econômica do governo.

Nesse período de liberalismo econômico, não foi somente a lei de Nova York a única declarada inconstitucional, invalidando a Suprema Corte, mas todas as leis que de alguma forma previam a intervenção do Estado na economia, ou seja, inclusive, na década de 1930, as leis que traziam medidas do New Deal, do então Presidente Roosevelt. É certo que foi justamente nesse período que houve um crescimento da doutrina da autocontenção judicial, que buscava defender uma maior deferência da Corte ao Congresso, já que este teria maior legitimidade democrática para decidir sobre questões substantivas, bem como sobre questões políticas.

A Era Lochner é considerada como exemplo de ativismo judicial conservador, porquanto, sob a égide do Estado Liberal, admitia a imparcialidade do Estado e aceitava como natural as diversidades existentes na Sociedade (CAMPOS, 2014, p. 61), sendo considerada ativista na medida em que interveio nas políticas tomadas pelo Executivo e pelo Legislativo, declarando as leis inconstitucionais, mas conservadora, uma vez que atuava de acordo com o Estado Liberal.

\footnotetext{
19 "In every case that comes before this court, therefore, where legislation of this character is concerned and where the protection of the Federal Constitution is sought, the question necessarily arises: is this a fair, reasonable and appropriate exercise of the police power of the State, or is it an unreasonable, unnecessary and arbitrary interference with the right of the individual to his personal liberty or to enter into those contracts in relation to labor which may seem to him appropriate or necessary for the support of himself and his family? Of course, the liberty of contract relating to labor includes both parties to it. The one has as much right to purchase as the other to sell labor." Lochner v. New York, 198 U.S. 45. Disponível em: <https://www.law.cornell.edu/supremecourt/text/198/45>. Acesso em: 03 nov. 2016.
} 
A mudança de entendimento da Suprema Corte, que era contrária ao New Deal, somente veio a acontecer em 1937, ${ }^{20}$ no caso West Coast Hotel v. Parrish, ${ }^{21}$ em que se decidiu no sentido de que a liberdade contratual não era ilimitada e que as considerações legislativas a respeito do bem-estar social justificariam certas restrições a essa liberdade, mais especificamente, proibindo salários demasiadamente mais baixos para as mulheres e declarando a constitucionalidade da lei de salário mínimo do Distrito de Colúmbia.

\begin{abstract}
A Constituição não fala de liberdade de contrato. Ela fala de liberdade, e proíbe a privação da liberdade sem o devido processo legal. Proibindo essa privação, a Constituição não reconhece uma liberdade absoluta e sem controle. A liberdade em todas as suas fases possui uma história e conotações. Mas a liberdade salvaguardada é a liberdade em uma organização social que requer a proteção da lei contra os males que ameaçam a saúde, a segurança, os costumes e a riqueza do povo. A liberdade sob a Constituição encontra-se necessariamente subordinada às restrições do devido processo, e uma regulamentação razoável face ao seu objeto, adotada nos interesses da comunidade, é devido processo. ${ }^{22}$
\end{abstract}

A partir de então, a Corte passa a aceitar todas as leis do New Deal (Wolfe, 1994, p. 162), e embora tenha continuado a exercer seu papel ativo e a fazer julgamentos substantivos a respeito das leis, mudou apenas a concepção do que seria arbitrário ou não razoável consoante sua concepção, analisando as leis sob o enfoque de seu objetivo político válido.

A cláusula do due process deixa de limitar a legislação social e a intervenção do Estado na economia, e passa a proteger o cidadão nos casos de liberdade de expressão, de reunião e religiosa (RODRIGUES, 1992, p. 229).

Outra decisão importante nesse período foi a proferida no caso Carolene Products Co. v. USA, segundo a qual a presunção de constitucionalidade das leis pode ser afastada se houver ofensa a um direito fundamental previsto na Constituição ou se a lei for contra minorias, mesmo que haja um objetivo público, mas que esse objetivo possa ser alcançado de outra forma.

Para Campos (2014, p. 64-65), ao aceitar essa posição, a Corte adota uma política de deferência à legislação em alguns casos, porém, assume um papel intervencionista e ativista quando se trata de violação aos direitos fundamentais, principalmente àqueles que protegem as minorias, pois, nesse caso, a jurisdição constitucional estaria apenas protegendo o processo democrático, o que se compatibilizaria com a ideia daqueles que defendem uma concepção procedimental de constituição.

\title{
4 A Corte Warren e a proteção dos direitos civis
}

Weinrib (2006, p. 99 e ss.) traz a Corte Warren (Warren Court) como exemplo do paradigma constitucional do pós-guerra nos Estados Unidos. Earl Warren foi Presidente (Chief Justice) da

\footnotetext{
20 Não obstante, já em 1934, a Corte, no caso Nebbia v. New York, a respeito de regulação do preço do leite pelo Estado de Nova York, já havia decidido que "[...] where private and public rights conflicted, the private must yield to the public" demonstrando já um começo de mudança de entendimento da Corte (WOLFE, 1994, p. 161).

21 West Coast Hotel Co. v. Parrish, 300 U.S. 379. Disponível em: <https://www.law.cornell.edu/supremecourt/text/300/379>. Acesso em: 10 nov. 2016.

22 West Coast Hotel v. Parrish (apud MELO, 2003, p. 77).
} 
Suprema Corte dos Estados Unidos no período de 1953 a 1969, estabelecendo uma Corte ativista e de proteção aos direitos humanos, especialmente das minorias. Alguns autores chegam a falar do período da Corte Warren como aquele da Revolução de Direitos (KECK, 2004, p. 71).

$\mathrm{Na}$ decisão de Brown v. Board of Education, ${ }^{23}$ por exemplo, a interpretação motivada pela Corte promoveu princípios de igual cidadania e de dignidade da pessoa humana, em oposição à decisão anterior ${ }^{24}$ que estabelecia a existência de hierarquias sociais naturais, permitindo meios de segregação racial nos trens e, por consequência, em escolas públicas. Desse modo, a decisão em Brown v. Board of Education superou (overruled) a decisão anterior, deixando claro que a segregação racial em escolas públicas era inerentemente desigual e que violava o princípio da igualdade (equal protection clause) previsto na $14^{\mathrm{a}}$ Emenda.

Essa decisão ajudou a desencadear o movimento de direitos civis nos Estados Unidos. Além disso, anulou diversas leis estaduais que propugnavam discriminação racial, incluindo aquelas que proibiam casamentos mistos, do ponto de vista racial (racially mixed marriages).

Ainda, outros casos importantes, relacionados a direitos fundamentais no pós-Guerra foram julgados e protegidos pela Corte Warren. A proteção do princípio democrático como "um homem, um voto" ocorreu na decisão Reynolds v. Sims, ${ }^{25}$ ou seja, foi consolidada a ideia de que o voto deveria ser proporcionalmente igual à população e não às áreas geográficas.

Do mesmo modo, o direito à privacidade foi reconhecido pela Corte Warren no caso Griswold v. Connecticut, ${ }^{26}$ no qual a Corte declarou a inconstitucionalidade de uma lei estadual que proibia informações sobre controle de natalidade e também preparou terreno para que no caso Roe v. Wade ${ }^{27}$ a Corte estabelecesse o direito ao aborto às mulheres.

\footnotetext{
23 No caso em tela foi alegado que a segregação entre crianças brancas e negras nas escolas públicas, baseada em raça, negava às crianças negras a igual proteção perante a lei garantida pela $14^{\mathrm{a}}$ Emenda. A suprema corte julgou inconstitucionais as leis estaduais que estabeleciam essa segregação, por entender que: "We conclude that in the field of public education the doctrine of "separate but equal" has no place. Separate educational facilities are inherently unequal. Therefore, we hold that the plaintiffs and others similarly situated for whom the actions have been brought are, by reason of the segregation complained of, deprived of the equal protection of the laws guaranteed by the Fourteenth Amendment. This disposition makes unnecessary any discussion whether such segregation also violates the Due Process Clause of the Fourteenth Amendment." "Nós concluímos que no campo da educação pública a doutrina do "separados mas iguais" não tem espaço. Estruturas educacionais segregadas são inevitavelmente desiguais. Por isto, nós sustentamos que os peticionários e demais indivíduos em situação similar, em favor de quem se instaurou ações, são, em função da segregação que contestam, privados da igual proteção perante o direito garantido pela décima quarta emenda. Esta disposição torna desnecessária qualquer discussão a saber se a segregação também viola a cláusula do devido processo legal da décima quarta emenda." Brown v. Board of Education, 347 U. S. 483 (1954). Disponível em: < http://caselaw.lp.findlaw.com/ scripts/ getcase.pl?court =us\&vol=347\&invol=483. > . Acesso em: 10 ago. 2010.

24 Plessy v. Ferguson, 163 U.S. 537, 16 S. Ct. 1138, 41 L. Ed. 256.

25 Nesse caso foi discutida a representação proporcional no Legislativo do Alabama, tendo sido sustentada a tese de que a "equal protection clause" exige nada menos do que uma representação substantivamente igual no Poder Legislativo, para todos os cidadãos, de todos os lugares e de todas as raças. Reynolds v. Sims, 377 U.S. 533, 84 S. Ct. 1362, 12 L. Ed. 2 d 506 (1964). Disponível em <http://caselaw.lp.findlaw.com/cgi-bin/getcase.pl?court =us\&vol=377\&invol=533>. Acesso em: 10 out. 2010.

26 A Suprema Corte invalidou lei do Estado de Connecticut que proibia o uso de contraceptivos por violar o direito à privacidade implícito na Primeira Emenda. Griswold v. Connecticut, 381 U. S. 479, 85 S. Ct. 1678, 14 L. Ed. 2 d 510 (1965). Disponível em: <http://caselaw.lp.findlaw.com/scripts/ getcase.pl?court=us\&vol=381\&invol=479>. Acesso em: 10 out. 2010.

27 Roe pede o direito de interromper sua gravidez por meio de aborto, eis que pela lei do Estado do Texas somente era permitido aborto para salvar a vida da mãe. A Corte considerou que o direito constitucional ao aborto se insere no direito à privacidade da $14^{a}$ Emenda e, portanto, a mulher teria total autonomia no $1^{\circ}$ trimestre, restando para os Legislativos estaduais a competência para legislar sobre a possibilidade de aborto nos demais períodos da gestação. Roe v. Wade, 410 U. S. 113,93 S. Ct. 705, 35 L. Ed. 2d 147 (1973). Disponível em: <http://caselaw.lp.findlaw.com/cgi-bin/getcase.pl?court=us\&vol=410\&invol=113>. Acesso em: 10 out. 2010.
} 
A respeito da importância da Corte Warren, Wolfe (1994, p. 258) ressalta que:

The Warren Court used the same approach to constitutional interpretation and judicial review, for the most part, but expanded the category of "fundamental rights" dramatically and undertook to establish broad social policy in a number of controversial areas. It became the most activist Court in American history and left a profound imprint on American life and law. ${ }^{28}$

Essa visão também é corroborada por Keck (2004, p. 71 e ss.), especialmente ressaltando os leading cases julgados pela Corte no ano 1963. No caso New York Times Co. V. Sullivan, ${ }^{29}$ a Corte deveria determinar pela primeira vez a dimensão das liberdades constitucionais de expressão e de imprensa, se elas limitariam o poder do Estado de reconhecer danos relativos a uma difamação relacionada à conduta de seu funcionário público. A Corte, pelo voto do Justice Brennan, expandiu o conteúdo da Primeira Emenda, determinando pela primeira vez um limite para a Lei estadual que previa crimes contra a honra (Libel Law), colocando a Corte no meio dos conflitos de direitos civis e estabelecendo que críticas aos funcionários de um governo são críticas ao governo e, portanto, não podem ser consideradas pessoais e eventualmente alguma difamação, mas, ao contrário, devem ser consideradas dentro do conteúdo protegido da liberdade de expressão e, consequentemente, da liberdade de imprensa.

Uma decisão importante da Suprema Corte americana, já na Era Warren, demonstrando o importante papel do judicial review na proteção dos direitos da minoria, pode ser encontrada no caso Brown v. Board of Education, julgado em 1954, no qual se decidiu pela inconstitucionalidade da lei que determinava a segregação racial de crianças nas escolas. ${ }^{30}$

Warren entendeu que quando um Estado assume a responsabilidade de garantir a oportunidade de educação nas suas escolas públicas, esta constitui um direito que deve ser acessível a todos, em igualdade de condições, e separar as crianças apenas por motivo racial priva crianças de grupos minoritários de iguais oportunidades educacionais, além de gerar sentimento de inferioridade quanto ao seu status na comunidade, o que pode contaminar seus corações e espíritos de modo irreparável, concluindo que facilidades educacionais separadas são inerentemente desiguais. ${ }^{31}$

Para além disso, a Corte não apenas decidiu a respeito do direito dos demandantes a ingressar em escolas reservadas a brancos, como também adotou uma atitude ativa no que diz respeito à execução de seu julgado, que, por questões estratégicas, somente ocorreu em 1955, quando, então, determinou

\footnotetext{
28 "A Corte de Warren usou a mesma abordagem de interpretação constitucional e de revisão judicial, na maior parte das vezes, mas expandiu a categoria de "direitos fundamentais" dramaticamente e assumiu a responsabilidade em estabelecer vasta política social em várias áreas controvertidas. Tornou-se a Corte mais ativista na história dos EUA e deixou uma marca importante na vida e no Direito Americanos.

${ }_{29}$ New York Times Co. V. Sullivan. 376 U.S. 254. Disponível em: <https://www.law.cornell.edu/supremecourt/text/376/254>. Acesso em: 08 nov. 2016.

30 "Sobre o princípio da igualdade, além de Brown v. Board of Education, já referido, a Corte de Warren decidiu em McLaughlin v. Florida que toda classificação racial é constitucionalmente duvidosa, devendo ser cuidadosamente analisada pela Corte. Em Loving v. Virgínia a Corte declarou inconstitucionais as leis estaduais que proibiam a união entre pessoas de diferentes raças. Em Baker v. Carr a Corte assegurou a igualdade entre brancos e negros na formação de distritos eleitorais." (BARACHO JÚNIOR, 2003, p. 325).

31 Brown v. Board of Education of Topeka. 347 U.S. 483. Disponível em: <https://www.law.cornell.edu/supremecourt/ text/347/483\# > . Acesso em: 10 dez. 2015.
} 
"[...] que todos os dispositivos de leis federais, estaduais ou municipais deviam ajustar-se ao mesmo" (RODRIGUES, 1992, p. 303), reconhecendo-se às autoridades escolares "[...] a principal responsabilidade na elucidação e resolução" (RODRIGUES, 1992, p. 303) dos problemas e dificuldades dessa transição para um sistema em que não houvesse mais discriminação racial, delegando aos tribunais distritais, pela proximidade, o poder de fiscalização do cumprimento da decisão pelas escolas locais. ${ }^{32}$

Dessa forma, a decisão da Suprema Corte acabou por proteger um grupo social e politicamente vulnerável, rompendo com a ideia de que toda interpretação deveria seguir a intenção dos fathers da Constituição e utilizando outros fundamentos que não jurídicos para a decisão, e o mais importante, atribuiu papel ativo ao Estado para dar cumprimento à decisão (CAMPOS, 2014, p. 72 e ss.).

Nesse caso específico, uma eventual consulta à população, majoritariamente racista, ou a seus representantes eleitos, em deferência ao princípio da democracia, significaria uma manutenção do status quo em detrimento de uma efetiva proteção a uma minoria negra. Até porque, o Judiciário encontrava-se em uma situação de imparcialidade melhor do que o Legislativo para a apreciação do caso narrado. Não teriam sido os políticos, nesse caso, imparciais, porquanto movidos por fortes questões não racionais sobre o racismo (CLÈVE, 2000, p. 26), razão pela qual não seria recomendável a postura da deferência no caso em tela.

A Corte demonstrou, dessa maneira, um claro ativismo judicial intervencionista nas funções do Legislativo e também do Executivo, com o propósito de garantia de um direito fundamental prestacional, como a educação, e mais, "[...] what the Court hoped to achieve was not so much the vindication of concrete individual rights (though they were involved), but the setting in motion of a vast social reform." (WOLFE, 1994, p. 262). ${ }^{33}$

O sentido de realização que surgiu com essa reforma bem-sucedida, de alto propósito moral, forneceu à Corte um momento de grande crédito em outras reformas substanciais, encabeçando, nos anos 1960, outras reformas que eram tidas como moralmente necessárias e em harmonia com os ideais mais amplos da Constituição, mesmo quando bases constitucionais específicas estavam bastante fracas. ${ }^{34}$ Isso estabeleceu o alto grau de valor substantivo da Constituição determinado pelo Judiciário.

Outro momento importante, em relação à Corte Warren, ocorreu no julgamento do caso Watkins v. United States, ${ }^{35}$ em que o Tribunal julgou os limites do poder do Congresso, especificamente, seu poder investigatório em caso de instauração de Comissão Parlamentar de Inquérito.

\footnotetext{
32 Não se pode esquecer de que a funcionalidade do modelo americano "[...] repousa no princípio do stare decisis, na força vinculante das decisões judiciais. Por força desse princípio, no momento em que a Supreme Court decide a respeito de qualquer questão constitucional, sua decisão é vinculante para todos os demais órgãos judiciais", adquirindo a decisão eficácia erga omnes (CLÈVE, 2000, p. 66).

33 "[...] o que a Corte esperava alcançar não era tanto a defesa de direitos concretos do indivíduo (embora estivessem envolvidos), mas o início de uma vasta reforma social."

34 "The sense of accomplishment arising from this successful reform of high moral purpose provided the court with a substantial momentum heading into the 1960s and made it possible for the Court to conceive of undertaking other substantial reforms, reforms that were felt to be morally necessary and in keeping with the constitution's broader ideals, even where specific constitutional underpinnings were quite weak." (WOLFE, 1994, p. 262).

35 Watkins v. United States. 354 U.S. 178. Disponível em: <https://www.law.cornell.edu/supremecourt/text/354/178>. Acesso em: 20 out. 2015.
} 
A Corte entendeu que o poder do Congresso de realizar investigações é inerente ao processo legislativo, não obstante, deveria ele respeitar alguns limites, concluindo, assim, que os poderes do Legislativo não são ilimitados (RODRIGUES, 1992, p. 310-311).

Sob esse enfoque, além de declarar a limitação do poder de inquérito do Legislativo, a Corte Warren também declarou que esse poder estava sujeito ao controle do Poder Judiciário, exercendo, mais uma vez, um controle judicial ativo, aplicando diretamente os valores relativos à liberdade e ao devido processo legal protegidos pela Constituição, garantindo que alguém que esteja respondendo um processo perante o Congresso tenha o direito de saber sobre o objeto da investigação e os motivos de ser interrogado. ${ }^{36}$

Já em 1962, outra decisão de grande importância proferida pela Corte Warren foi a relativa ao caso Baker v. Carr, ${ }^{37} \mathrm{em}$ que se discutiu a divisão dos distritos eleitorais do Estado de Tennessee (WOLFE, 1994, p. 265 e ss.), entendendo que esta não era uma questão meramente política, ${ }^{38}$ mas que deveria estar sujeita ao controle judicial, posto que tinha a ver tanto com o princípio da separação de poderes quanto com o princípio da igualdade. ${ }^{39}$

Continuando com essa mesma discussão sobre representação política dos cidadãos, em 1964, no caso Reynolds v. Sims, ${ }^{40}$ Warren declarou que a representação democrática devia se basear no princípio do "um homem-um voto" (WOLFE, 1994, p. 266), haja vista que, a seu ver, a discriminação no peso do voto em razão do local de residência negava uma proteção igual (equal protection), tanto quanto a discriminação racial. E do mesmo modo que aconteceu no caso Brown, além de rejeitar a intenção original of the fathers, a Corte determinou a execução da decisão pelas cortes estaduais baseada nos princípios gerais de equidade.

Warren levantou as seguintes questões:

O conceito da igual proteção tem sido tradicionalmente visto como a exigência de tratamento uniforme de pessoas que se encontram na mesma situação em relação à ação governamental questionada ou desafiada. No que se refere à alocação da representação legislativa, todos os votantes, como cidadãos de um Estado, encontram-se na mesma situação, independentemente de onde moram. Nenhum critério sugerido para a diferenciação entre cidadãos é suficiente para justificar qualquer discriminação em relação ao peso de seus votos, a menos que relevante para os propósitos permissíveis da distribuição eleitoral. Como atingir a justa e efetiva representação para todos os cidadãos é o alvo admitido da ordenação eleitoral, nós concluímos que o princípio da igualdade garante a oportunidade de

\footnotetext{
${ }_{36}$ Watkins v. United States. 354 U.S. 178. Disponível em: <https://www.law.cornell.edu/supremecourt/text/354/178>. Acesso em: 20 out. 2015.

37 Baker v. Carr. 369 U.S. 186. Disponível em: <https://www.law.cornell.edu/supremecourt/text/369/186>. Acesso em: 05 nov. 2016.

38 Veja-se que, no Brasil, Rui Barbosa defendia a competência do Supremo Tribunal Federal para "apreciar qualquer matéria que envolvesse lesão a direitos fundamentais, ainda que tal lesão estivesse calcada em controvérsias políticas." (BARACHO JÚNIOR, 2003, p. 335).

39 "In Baker v. Car, the Court indicated its willingness to get involved in what Justice Frankfurter had termed this 'political thicket'. It engaged in a long analysis of the political-questions doctrine, arguing that its different aspects were all functions of the principle of separation of powers, and held that none were involved in this question since it concerned action by a state government, not the coordinate branches. 'Republican guarantee' cases were basically irrelevant because the provision involved here - the equal-protection clause - (unlike the guarantee clause) had well developed and familiar judicial standards." (WOLFE, 1994, p. 266).

40 Reynolds v. Sims. 377. U.S. 533. Disponível em: <http://caselaw.findlaw.com/us-supreme-court/377/533.html>. Acesso em: 04 nov. 2016.
} 
igual participação para todos os votantes nas eleições dos legisladores estaduais. Diluir o peso dos votos em virtude do local de residência viola direitos constitucionais básicos protegidos pela Décima-Quarta Emenda, assim como discriminações odiosas baseadas em fatores como raça ou status econômico. ${ }^{41}$

Nessa decisão, verifica-se um típico caso de ativismo judicial para a garantia do processo democrático, não obstante, com julgamento de valores substantivos a respeito, porquanto houve uma valoração pelo Poder Judiciário de que o princípio da igual proteção, garantindo um tratamento uniforme a todas as pessoas, também lhes concedia o direito à igual participação nas eleições.

É possível afirmar a desconfiança da Corte em relação ao próprio processo democrático como apto a reparar eventual violação à Constituição, visto que essa inconstitucionalidade também afetava o funcionamento adequado do processo democrático, e os legisladores não eram confiáveis para adequar a legislação, porque eram os próprios interessados e beneficiados pela lei inconstitucional, estando, portanto, "[...] a autoridade judicial em melhores condições para atuar com necessária imparcialidade", bem como porque as questões eram justamente as credenciais democráticas do Poder presumivelmente mais democrático que estavam em questão. ${ }^{42}$

O grande efeito dessas decisões, constata Wolfe (1994, p. 268), foi seu impacto educativo, reforçando os ideais mais equitativos de democracia contra a concepção tradicional de democracia majoritária, protegendo-se, assim, os grupos minoritários.

Também em memorável julgamento, Brandeburg v. Ohio, em 1969, a Corte se deparou com a colisão entre direitos fundamentais, especialmente no que diz respeito ao direito de liberdade de expressão, enquanto seu exercício encontra apoio majoritário, não há qualquer problema; apesar disso, se quando da manifestação da liberdade de expressão houver um repúdio por grande parte da população, é que a Corte deve garantir esse direito fundamental, independente de pressões políticas ou passionais, ${ }^{43}$ uma vez que, ao permitir um amplo debate de ideias, acaba por garantir e dar fun-

\footnotetext{
41 And the concept of equal protection has been traditionally viewed as requiring the uniform treatment of persons standing in the same relation to the governmental action questioned or challenged. With respect to the allocation of legislative representation, all voters, as citizens of a State, stand in the same relation regardless of where they live. Any suggested criteria for the differentiation of citizens are insufficient to justify any discrimination, as to the weight of their votes, unless relevant to the permissible purposes of legislative apportionment. Since the achieving of fair and effective representation for all citizens [377 U.S. 533, 566] is concededly the basic aim of legislative apportionment, we conclude that the Equal Protection Clause guarantees the opportunity for equal participation by all voters in the election of state legislators. Diluting the weight of votes because of place of residence impairs basic constitutional rights under the Fourteenth Amendment just as much as invidious discriminations based upon factors such as race, Brown v. Board of Education, 347 U.S. 483, or economic status, Griffin v. Illinois, 351 U.S. 12, Douglas v. California, 372 U.S. 353. Our constitutional system amply provides for the protection of minorities by means other than giving them majority control of state legislatures. And the democratic ideals of equality and majority rule, which have served this Nation so well in the past, are hardly of any less significance for the present and the future. Disponível em: <http://caselaw.findlaw.com/us-supreme-court/377/533.html>. Acessoem: 04 nov. 2016.

42 Nesse sentido, Wolfe (1994, p. 268) faz as seguintes considerações: "Again, though, the relative popularity of, and the successful obtaining of compliance with, the reapportionment decisions helped to increase the Court's self-confidence in its ability to initiate and guide social reform. It especially exemplified the Court's commitment to exercise scrutiny in cases where the integrity of the political process was a stake. In such cases, after all, there was less reason to defer to a presumably more democratic branch, since the very democratic credentials of that branch was the issue."

43 Para Moro (2002, p. 31), "[...] os direitos e liberdades fundamentais não podem ser de todo 'funcionalizados', ou seja, subordinados a determinados fins. Não é difícil defender o exercício de direitos fundamentais que contam com amplo apoio popular. Os casos difíceis surgem quando os direitos fundamentais entram em colisão com legítimos interesses comunitários. Nesses casos é que as cortes podem mostrar seu valor, optando fundamentadamente por um ou por outro. Se é certo que os direitos fundamentais não são absolutos, também é correto que não podem ser sacrificados sempre que colidirem com interesses comunitários, senão restaria descaracterizada a idéia central do Estado de Direito, ou seja, o mandamento kantiano de que o indivíduo é um fim em si mesmo, o que gera a obrigação de que seus direitos sejam levados a sério."
} 
cionamento ao próprio processo democrático. Na verdade, é possível pensar nesse caso como aquele em que se definem os limites da liberdade de expressão e do discurso de ódio.

O caso trata de um líder do Ku Klux Klan que chegou à Corte por defender a possibilidade de crime, sabotagem, violência ou métodos ilegais de terrorismo como forma de forçar uma reforma política e industrial, defendendo um criminalismo sindical. A questão, então, foi tratada pela Corte no sentido de que a liberdade de expressão somente poderia ser proibida quando buscasse incitar e, possivelmente, produzir iminentes atos ilegais (WOLFE, 1994, p. 278).

A contribuição da Corte Warren também merece destaque em relação aos direitos fundamentais de igualdade, liberdade de discurso, liberdade de imprensa, relação entre Estado e Igreja, direitos econômicos e federalismo.

Segundo Wolfe (1994, p. 278), as grandes verdades da vida política americana segundo a Corte Warren, como a liberdade individual e a igualdade, eram tão fortes que o regime deveria tratar da tolerância aos inimigos da liberdade não apenas como uma questão de política pública, mas como uma questão constitucional.

Cabe, aqui, ressaltar que a Corte Warren buscou privilegiar a justiça em busca de uma igualdade real em detrimento de uma igualdade meramente formal, pois ao proteger as minorias, a Suprema Corte procurou discriminá-las de forma positiva, para lhes assegurar uma igualdade material. Campos (2014, p. 78) analisa que o conjunto de decisões da Corte Warren é importantíssimo para o debate contemporâneo acerca do ativismo judicial, na medida em que avançou na proteção da liberdade fundamental e da igualdade social.

Apesar de uma visão geralmente positiva em relação à Corte Warren, há também algumas críticas a respeito. As principais críticas vieram de dentro da própria Corte, pelos votos dissidentes dos Justices John Marshal Harlan e Hugo Black, especialmente entendendo que a Corte estava indo longe demais ao proteger direitos não enumerados à privacidade em casos como Grisold v. Connecticut e defendendo uma leitura textual e originalista da Constituição, adotaram uma posição conservadora, criticando os colegas de ignorar os próprios limites do papel da Corte que estava reescrevendo a Constituição para atender suas próprias finalidades (KECK, 2004, p. 67-71).

\section{0 ativismo judicial da Corte Burger}

Já em 1973, sob a presidência do Chief Justice Burger, encontra-se um novo exemplo de ativismo judicial, no qual a Suprema Corte protege direitos não enumerados na Constituição americana, com base na $9^{a}$ Emenda.

A $9^{a}$ Emenda à Constituição americana estabelece que: "[...] the enumeration in the Constitution, of certain rights, shall not be construed to deny or disparage others retained by the people", 44 o que é pró-

\footnotetext{
44 Disponível em: <http://www.house.gov/Constitution/Amend.html>. Acesso em: 01 jul. 2005. "A enumeração nesta constituição de certos direitos não deve ser interpretada para denegar ou depreciar outros retidos pelo povo." Essa norma se encontra prevista no artigo 5o, \20, da Constituição Federal brasileira: "Os direitos e garantias expressos nesta Constituição não excluem outros decorrentes do regime e dos princípios por ela adotados, ou dos tratados internacionais em que a República Federativa do Brasil seja parte."
} 
prio de uma Constituição escrita presente num país com tradição no common law, que, paralelamente aos direitos expressos e implícitos no texto constitucional, convive com a presença de direitos e princípios constitucionais inferidos das decisões judiciais e das práticas constitucionais ao longo da história.

Foi com base nessa Emenda que a Corte Burger, no caso Roe v. Wade, reconheceu o direito à privacidade, não previsto expressamente na Constituição, como um direito fundamental adicional, "[...] operando uma hermenêutica em que a Constituição é, para todos os efeitos, uma obra aberta" (MELLO, 2003, p. 85), concluindo que a mulher teria direito à interrupção voluntária da gravidez.

Mas não foi somente uma interpretação criativa que levou a Corte a decidir dessa maneira, mas também a integridade com o precedente anterior, no caso Griswold v. Connecticut, ${ }^{45}$ ainda na época da Corte Warren, que já havia reconhecido o direito à privacidade às mulheres, tendo a Corte declarado a inconstitucionalidade de uma lei estadual que proibia informações sobre controle de natalidade, tendo já preparado terreno para que no caso Roe v. Wade a Corte estabelecesse o direito ao aborto às mulheres.

Aqui, mais uma vez se demonstra a importância do papel criativo da Suprema Corte americana, ao determinar valores para normas abstratas contidas em seu Texto Constitucional por meio de recursos à doutrina política.

A importância da decisão também ocorre no sentido de tornar mais robustos os debates jurídicos e políticos que aconteceram como um processo de diálogo com o Legislativo e a própria sociedade, no qual a Corte devolve o tema, num processo de idas e vindas, que não se esgota na possibilidade de "última palavra" (MENDES, 2008, p. 134-135).

\section{Considerações Finais}

Verifica-se, das experiências da Suprema Corte americana, principalmente no período da Corte Warren, que o ativismo judicial e, por consequência, o papel criativo dos juízes constitucionais, na maioria das vezes, não esteve a restringir o processo democrático, ao contrário, permitiu sua manutenção e eficiência.

Para além disso, muitas vezes, a Corte se imiscuiu em problemas que levavam a um julgamento de valores políticos e morais, que, de modo algum, contrariaram o processo democrático, eis que conseguiu dar força e efetividade aos direitos fundamentais previstos em seu Bill of Rights, mesmo que isso lhe custasse ficar contra o posicionamento majoritário do povo, como nos episódios que envolveram os temas segregação racial e aborto.

O judicial review americano é o maior exemplo de ativismo judicial da história constitucional moderna, na medida em que, baseado em uma constituição rígida, porém sintética, e calcado em princípios e valores substantivos abertos, permitiu e permite à jurisdição constitucional a definição material ou substantiva das cláusulas de conteúdo aberto presentes na Constituição.

\footnotetext{
45 A Suprema Corte invalidou a lei do Estado de Connecticut que proibia o uso de contraceptivos por violar o direito à privacidade implícito na Primeira Emenda. Griswold v. Connecticut, 381 U. S. 479, 85 S. Ct. 1678, 14 L. Ed. 2 d 510 (1965). Disponível em: <http://caselaw.lp.findlaw.com/scripts/ getcase.pl?court=us\&vol=381\&invol=479>. Acesso em: 10 out. 2010.
} 
Dessa forma, o Poder Judiciário, exercendo um papel tipicamente ativo no contexto norte-americano, determinou o conteúdo de direitos fundamentais importantes, conquanto isso importasse em limitações aos demais Poderes, uma vez firmadas a supremacia e a rigidez da Constituição ou ainda que isso implicasse tomada de decisões políticas pelo Judiciário.

Embora recentemente pareça haver uma liberdade de criação de diferentes definições para a expressão ativismo judicial como sinônimo de corte arbitrária (CAMPOS, 2014, p. 49), não é o que se defende no presente artigo. Ativista é a Corte que não é deferente, que enfrenta as questões de direitos fundamentais que lhe são colocadas, mesmo que estas envolvam decisões sobre questões políticas. Na verdade, alguns autores usam a expressão ativismo judicial como meio de criticar a Corte por decidir de uma maneira da qual o comentador discorda, colocando de forma implícita o fato de a Corte ter ido além de seu papel judicial (ROACH, 2007, p. 70).

A história do ativismo judicial da Suprema Corte americana mostra que o ativismo em si não é algo positivo ou pejorativo, progressista ou conservador, tendo sido parâmetro quer para proteger direitos fundamentais, quer para restringi-los.

\section{Referências}

ACKERMAN, Bruce. We The People: Foundations. Massachusetts: The Belknap Press of Harvard University Press, 1991.

BARACHO JÚNIOR, José Alfredo de Oliveira. A interpretação dos direitos fundamentais na Suprema Corte dos EUA e no Supremo Tribunal Federal. In: SAMPAIO, José Adércio Leite (Org.). Jurisdição constitucional e direitos fundamentais. Belo Horizonte: Del Rey, 2003.

BARBOZA, Estefânia Maria de Queiroz. Precedentes Judiciais e Segurança Jurídica: limites e possibilidades para a Jurisdição Constitucional brasileira. São Paulo: Saraiva, 2014.

BARROSO, Luís Roberto. O controle de constitucionalidade no direito brasileiro: exposição sistemática da doutrina e análise crítica da jurisprudência. São Paulo: Saraiva, 2004.

BICKEL, Alexander M. The Least Dangerous Branch: The Supreme Court at the Bar of Politics. $2^{\text {nd }}$ ed. New Haven: Yale University Press, 1986.

CAMPOS, Carlos Alexandre de Azevedo. Dimensões do Ativismo Judicial do STF. Rio de Janeiro: Forense, 2014.

CAPPELLETTI, Mauro. O controle judicial de constitucionalidade das leis no direito comparado. Porto Alegre: Fabris, 1984.

CLÈVE, Clèmerson Merlin. A fiscalização abstrata da constitucionalidade no direito brasileiro. 2. ed. São Paulo: Revista dos Tribunais, 2000.

DWORKIN, Ronald. Taking rights seriously. Cambridge: Harvard University Press, 1978.

ELY, John Hart. Democracy and Distrust. Fourteenth printing. Cambridge: Harvard University Press, 2002. 
FAVOREU, Louis. As Cortes Constitucionais. São Paulo: Landy Editora, 2004.

HAMILTON, Alexander. O federalista. 2. ed. Campinas: Russell Editores, 2005.

KECK, Thomas M. The Most Activist Supreme Court in History: The road to modern judicial conservatism. Chicago: The University of Chicago Press, 2004.

KOZICKI, Katya. Conflito e estabilização: comprometendo radicalmente a aplicação do direito com a democracia nas Sociedades Contemporâneas. 2000. Tese (Doutorado em Direito)-Universidade Federal de Santa Catarina, Florianópolis, 2000.

MELO, Manuel Palácios Cunha. A Suprema Corte dos EUA e a judicialização da Política: notas sobre um itinerário difícil. In: VIANNA, Luiz Werneck (Org.). A democracia e os Três Poderes no Brasil. Belo Horizonte: Ed. UFMG, 2003.

MENDES, Conrado Hübner. Direitos fundamentais, separação de poderes e deliberação. 2008. Tese (Doutorado em Ciência Política)-Universidade de São Paulo, São Paulo, 2008.

NELSON, William E. Marbury v. Madison: the origins and legacy of judicial review. Kansas: University Press of Kansas, 2000.

ROACH, Kent. Judicial Activism in the Supreme Court of Canada. In: DICKSON, Brice (Ed.). Judicial Activism in Common Law Supreme Courts. Oxford: Oxford University Press, 2007.

RODRIGUES, Lêda Boechat. A Corte Suprema e o Direito Constitucional Americano. 2. ed. Rio de Janeiro: Civilização Brasileira, 1992.

VIEIRA DE ANDRADE, José Carlos. Os Direitos Fundamentais na Constituição Portuguesa de 1976. 2. ed. Coimbra: Almedina, 2001.

TRIBE, Laurence H. The Invisible Constitution. New York: Oxford University Press, 2008.

TUSHNET, Mark. The United States of America. In: DICKSON, Brice (Ed.). Judicial Activism in Common law Supreme Courts. New York: Oxford University Press, 2007.

WEINRIB, Lorraine E. The postwar paradigm and American exceptionalism. In: CHOUDHRY, Sujit (Ed.). The migration of constitutional ideas. Cambridge: Cambridge University Press, 2006.

WHITTINGTON, Keith E. "Interpose your friendly hand": political supports for the exercise of Judicial Review by the United States Supreme Court. American Political Science Review, v. 99, i. 4, 2005.

WOLFE, Christopher. The Rise of Modern Judicial Review: from constitutional interpretation to judge-made law. Maryland: Littlefield Adams Quality Paperbacks, 1994.

Data da submissão: 03 de setembro de 2015 Avaliado em: 08 de abril de 2016 (AVALIADOR A) Avaliado em: 05 de julho de 2016 (AVALIADOR B) Avaliado em: 16 de agosto de 2016 (AVALIADOR C) Avaliado em: 20 de agosto de 2016 (AVALIADOR D) Aceito em: 28 de novembro de 2016 
